\title{
From WaLKING BaNKERS TO BlockCHAIN TECHNOLOGY The History of PAyMent Systems
}

\author{
Andrea KRISKÓ, Tibor TATAY \\ Széchenyi István University, H-9026 Győr, Egyetem tér 1.
}

\begin{abstract}
The technique and technology of payment settlement systems has completed an enormous journey from the $18^{\text {th }}$ century to modern times. Nowadays, we have gone from bilateral settlements to global payment systems. Numerous payment options are available to us, from paper based settlements to mobile wallets. In my study, I am primarily tracking the development of the technology on the basis of the payment systems of the USA, introducing the primary open and closed loop systems, as well as the changing customer needs which have brought the bank card and Bitcoin to life.
\end{abstract}

Keywords: payment systems, bank card, smartphone wallet, Bitcoin

\section{THE CRADLE OF DEVELOPMENT: LONDON AND NEW YORK}

Based on early accounts, the idea of creating a clearing house arose by accident in the $17^{\text {th }}$ century. In the 1670 s, financial institutions employed brokers walking around the City of London, walking from bank to bank to gather cheques and bills. Bankers living on opposite ends of the city then decided to meet in a cafe downtown at the same time every day. Several people considered this idea worth emulating, so consequently the bankers were renting a separate room soon enough to enable them to conduct business uninterrupted. (Thralls, 1916)

To avoid settlement errors and to manage a separate set of books, they had hired a man to keep an eye on the transactions. This is how the London Clearing House was born, perhaps the largest clearing house of the time. The idea of a clearing house had spread soon; in 1853, the New York Clearing House was founded. After New York, Boston, Pittsburgh, Philadelphia and Chicago also operated a clearing house each, just to mention the larger ones.

At this time, there were already registered settlement venues that were also operating on a voluntary basis, even though many believed that the solution was not a clearing house, but rather, the strengthening of legal regulations (Thralls, 1916). Naturally, at this time, settlement transactions were still undertaken on a paper basis, the forwarding of checks and drafts held numerous challenges and this may have had an effect on the timeliness of the transactions as well. The City Department performed general settlements and it was this unit which had issued the client codes (joining clearing partners received serial numbers in a chronological order). The settlements of the financial institutions were listed under codes, authenticated with signature and seal. 
The clearing house prepared a carbon copy of the certificates summary of their transaction volume, but the blank forms were not uniform at the time and changed from clearing house to clearing house.

Back then, settlements were none other than an insane dash by the bankers to the clearing house, where numbered tables were lined up in parallel rows. Now, the exchange rooms/dealing rooms of brokerage firms are set up similarly. When every banker arrived and put down their package of drafts, settlements could begin.

At that time, the deadline for settlements was two o'clock in the afternoon, the bankers received their certificates and they went back to the bank. On the basis of the received certificate, the bank debited and credited the accounts. It significantly reduced the risk of robbery that the bankers were not walking around with money, but rather, with certificates.

Erroneous settlements were fined and bankers were levied fines as well for breaches of their obligations. The fines ranged from 10 cents to 5 dollars, depending on the severity of the offense. Additionally, the clearing house also issued loan certificates, with strict deadlines. The small banks did not participate in clearing operations through the clearing house; they settled with their partners via the framework of bilateral agreements.

The next developmental step was the founding of the Country Clearing House ${ }^{1}$ in the USA. The objective of the Country Clearing House was the reduction of costs deriving from the distribution of checks; in addition to speeding up physical movement and clearing operations, the institution gained a prominent role in the development of the correspondent banking system. Its members forwarded the banking information, account numbers, identifiers, addresses and the data required for settlement to each other on cards, significantly simplifying the accuracy of settlements.

The clearing house prepared a carbon copy of the certificates at that time; authentication took place via seal and signature in all cases. The members of the clearing house paid a fee to the clearing house each month, based on the volume of the clearing; this also operates on a similar principle now. The speed of development shows that 233 clearing houses worked in the US in 1905 (Thralls, 1916).

A significant waystation along the developmental path of clearings was the introduction of the MICR system (magnetic ink character recognition) at the end of the 1950s - beginning of the $60 \mathrm{~s}^{2}$, the MICR-code, which allowed the identification of the type of the document (check, vouchers); the bank code, the bank account number, the check number, the verification amount and a verification number/identifier could also be found. The system enables the direct entry of data into the data processing system. Contrary to other technologies, these characters were also in human-readable format (the ink generally contains iron oxide, the ratio of scanning error is under $1 \%$ ).

The settlements of early clearing houses were typified by the designated-time of the settlement; clearing and financial settlement took place at a given time every day.

\footnotetext{
${ }^{1}$ The first large scale open loop system in the USA.

2 Magnetic ink character recognition (MICR) - the technology was primarily developed for the banking sector, to simplify document processing and verification. (Wikipedia, n.d.)
} 
The Belgium based correspondent bank system named Worldwide Interbank Financial Telecommunication (SWIFT) was founded in Brussels in 1973 by 293 banks, with the support of 15 countries. It began its active operations in 1977 with the utilization of telex technology and soon gained a defining role in conducting cross-border settlements. The system can be credited to this day with the application of the standardized message format, which comprises the stable foundation of international settlements today as well. Today, SWIFT connects 11,000 institutions of approximately 200 countries with its network. The message standards cover the comprehensive totality of instruments in capital and equity markets. The message protocol can be divided into the following units: SWIFTNet Realtime, SWIFTNet InterAct Store and Forward, SWIFTNet FileAct Realtime, SWIFTNet FileAct Store and Forward and SWIFTNet Brows. Continuous settlement characterizes the operation of SWIFT, the forwarding of messages is practically taking place on a continuous basis while in operation. (The frequency of the beneficiary bank's bookkeeping of transactions on the basis of received messages is a different issue.) (Scott and Zachariadis, 2012)

In the 1970s, settlements through the Automated Clearing House began to replace bilateral agreements gradually in domestic payment transactions (Benson and Lofteness, 2017). This is how multilateral settlements developed between parties. It meant a significant advancement and improvement in speed in the realm of check settlements that in the 1980s and 1990s cameras had been affixed to check sorting systems which also recorded the image of the check. The goal was the reduction of expenses; from that point onward, the parties exchanged the image of the check over the course of settlement. At this time, the transportation and long-term storage of checks were still a problem (image scanning was not yet equivalent with the paper-based check, this was only resolved by Act 21 of 2004) (Federal Reserve Banks, n.d.). The banks began to implement „,check image clearing" en-masse in 2007, but by 2010, based on Federal Reserve data, 99\% of check clearings were already undertaken in this manner. With the development of ACH and mobile payments, however, check traffic is decreasing continuously; the $\mathrm{Y}$ and $\mathrm{X}$ generations already prefer debit cards and mobile wallets, as well as online payments. The younger generations (born after 1946) do not utilize the services of bank branches as often, either; they are primarily characterized by online shopping and the search for online solutions. The users of digital currencies are also found to a significant degree among young adults, approximately $60 \%$ of Bitcoin users are under 35 years of age.

\section{BANK CARDS AND POS PAYMENT}

The need for instant payment and convenience brought to life the still rather popular bank cards. The appearance of bank cards in the United States can be placed at around the 1950s and 1960s. A common characteristics of bank cards was a standardized size and plastic material, as well as a magnetic strip or chip. Diners Club and American Express charge cards became widespread in the 1950s, followed by numerous business ventures. These are examples of closed loop payment systems, but the credit card issued by Sears also belongs to this category. The first ATM cards were also born in the 1970s; these were cards equipped with a PIN number, suitable for obtaining cash from a 
checking account. This is a significant milestone because this is when we can start talking about cash withdrawals without a signature (Schropfer, 2010). The ATM network became truly wide-spread and accessible throughout the United States during the 1980s.

The appearance of bank cards also represented a convenience for the banks; their operational costs decreased significantly, teller traffic also consumed significantly fewer resources. It is no coincidence that the largest supporter of technological innovations is the banking sector and financial institutions, as they are the ones who are the direct and largest beneficiaries of systems that are developing there. The risks go down, the volume of settlements increases continuously, while at the same time, the processing time of transactions decreases steadily and continuously. A dominant proportion of bank card transactions operates pursuant to end of day settlements. Generally, the banks freeze the utilized amount on the client accounts until the time of settlement.

Cards issued by banks, prepaid cards and network branded cards can all be classified under open loop payment systems, with their main characteristic being that an unlimited number of users can join the network through an intermediary (bank). Another typical example of closed loop networks is the gift card or loyalty card, which is exclusively available to the customers of the given department store or store; nowadays it is available among the services of any larger retail chain. It is a disadvantage of closed loop systems that the expansion is slower here and the use of the cards is also limited.

The system of Point of Sale (POS) payments developed in parallel with the appearance of bank cards. The use of card reader terminals became widespread rather quickly, the payments became authenticated initially with signature, later via a PIN code. Nowadays, we can even pay without physical contact, with the aid of NFC technology, we can even use our mobile phone in addition to our bank card without any problems. The installation of terminals capable of non-contact payment has not taken place in many locations yet, in spite of the fact that it is essentially not expensive and does not require an extra investment.

Under the aegis of convenience and speed, in 2013, web credit services were also introduced in the United States, enabling instant web based crediting for the partner.

With regard to international settlements, the creation of the FED Global settlement system in the USA was significant. This payment system enables the performance of cross-border transactions into other countries in the case of pension payments. The payment target nations are primarily Canada and the United Kingdom. The transactions are conducted by the ACH; the payment mechanism is identical to domestic payments. The advantage of the system is its inexpensive nature and standardized format; since 2009, a separate transaction type has provided the settlement of Fed Global pension payments. (International ACH Transaction) (BIS, 1998)

\section{SMARTPHONE WALLET}

The "mobile wallet" application in the world of smartphones ${ }^{3}$ appeared soon, providing/impacting numerous advantages versus traditional bank card payments.

\footnotetext{
${ }^{3}$ By smartphone, we are referring to devices capable of NFC (Near Frequency Communication), equipped with Trusted Service Manager function and Universal integrated circuit card and an internet browser, operating on a GSM network and supplied with an operating system.
} 
Mobile wallet payments are fundamentally secure, as the identification of the owner of the telephone is self-evident. It is an advantage of the mobile wallet that at the time of payment, on the basis of available price discounts, it ranks payment methods (based on card or payment network); with a single device, bank cards, loyalty cards and coupons are equally accessible. The mobile wallet is an empty wallet which can be loaded with tools as the user wishes (bank card, credit card, loyalty card, coupons). In this way, the conditions of payment become easily accessible and personalized. (National Bank of Romania, 2016)

\section{LARGE VALUE PAYMENT SYSTEMS}

Contrary to other developed industrial nations (where the national bank operates an RTGS system), in the USA, to conduct large sum transfers, two systems are actually in operation. One of them is the FED Wire transfer system accessible to banks and financial institutions, and the other is the CHIPs (Clearing House Interbank Payment System) operated by large banks (owned by The Clearing House). The FED's system is a classical RTGS system, with guaranteed payment and performance, with an instant gross based settlement. In numerous countries internationally, financial institutions, banks and brokerage firms use wire transfers in the case of B2B transfers. Private clients only tend to use it when paying for real estate, as the payment orders are final, non-revocable and immediate. The settlement chain is rather simple, on one end of the transaction, the paying party and its bank are located, on the other, the bank of the receiving party, as well as the receiving party. Due to the nature of the transactions, however, to conduct these transactions, the banks pay particular attention to the four-eye principle in effect. The FED Wire Transfer has been in operation electronically since 1981; previously, the data were communicated among the banks by telex and fax. Contrary to the foregoing, CHIPs is working on a net basis, it is not an RTGS system. The CHIPs began its operation in 1970, thereby replacing paper based settlements.

Generally, RTGS systems are owned by national banks and they operate them, but in Canada and the United Kingdom, it is the private sector that plays its part in the operation of the payment systems.

The first RTGS system in Poland was SORB (Bank Accounts Servicing System), which was launched on 5April, 1993 (Benson and Lofteness, 2017). In Hungary, the "Valós Idejü Bruttó Elszámolási Rendszer" (Real Time Gross Settlement System) began its operation on 3 September, 1999. The European Union's TARGET system also began its journey in 1999, developed from the interlinking system connecting the respective national banks of member states. The ReGIS was introduced relatively late in Romania, in April of 2005; this was the first real-time payment system (Guttmann, 2014). Thanks to its broad bank branch network, Russia only introduced its instant payment system, the BESP, in 2007.

Nowadays, the reign of POS payments is undeniable, it has opened up new horizons without physical contact for bank cards and virtual cards. The primary factors influencing the development of payment systems were the creation of mobile applications, the Internet, the appearance of smartphones, the booming of mobile 
and online commerce, the development of POS terminals, NFC technology, authentication technology and the appearance of QR codes, iPhones equipped with chip cards and chips, as well as various payment platforms. Concomitant to development in recent decades was the rapid improvement of fraud prevention and risk management. Check and document imaging technologies assisted automation, reducing shipping costs and speeding up settlement. (Bailey, 2015)

\section{CRYPTO CURRENCIES - BITCOIN TECHNOLOGY}

The latest generation of payments is comprised of payments performed via digital currencies. Nowadays, as many as 1700 currencies exist in virtual space and the technology of these settlements significantly varies from that of traditional money transfers. There is no actual wealth, gold or other security behind digital currencies, their use is based on trust. It is a condition for payment that the service provider or seller accepts the given digital currency as payment. It is a significant innovation of Bitcoin (hereinafter: BTC) technology that there is no centralized system, clearing house or platform where the payments are performed, but rather processing takes place on the devices of system users (PC, mobile, hardware). (Nakamoto, n.d.)

The existence of digital currencies is legitimized by belief; they carry higher risk than traditional currencies, as there is no central regulatory body or issuer and they are not tied to a nation or organization. BTC is supported by the database distributed by the nodes of its peer-to-peer ${ }^{4}$ network (Benson and Lofteness, 2017). The infrastructure is provided by the users of the payment system; they provide the resources for the operation of the system. This is the least bureaucratic system, it does not require the opening of an account and the verification of one's identity, minors can also use the system, it is sufficient to download the application, establish a BTC address and use the private key. The settlement of Bitcoin and other digital currencies fundamentally cannot be classified under any of the classical settlement types, the settlement of transactions takes place depending on the load level of the system/network, essentially within one hour.

\section{CONCLUSIONS}

It can thus be stated that over the course of the past 200 years, payment technology has undergone continuous changes. The internet harbors unlimited opportunities in revolutionizing payment systems. Thanks to digital currencies, a new form of financial culture is beginning to emerge, one in which the young also demand a place for themselves. The development of consumer requirements assists the spread of mobile wallet functions more and more; with the spread of mobile devices, payment options are easily personalized. Nowadays, we have gone from bilateral settlements to global payment systems.

\footnotetext{
${ }^{4}$ By the term peer-to-peer network, a network composed of elements on an identical level; there is no superior or dominant element in the network, the network data is stored by the computers of the users.
} 


\section{REFERENCES}

Bailey, D. (2015): Bitcoin Guide for Beginners: The Simple And Proven Bitcoin Trading Guide for Making Money with Bitcoins. Amazon, Kindle Edition, ASIN: B00U3Z4ZDU 27. p.

Benson, C.C., Lofteness, S. (2017): Payment Systems in the U.S. Third Edition, San Francisco: Glenbrook Press, ISBN 978-0-9827897-5-9. 487. p.

BIS (1998) Managing change in payment system. Policy Papers No. 4., Basle: Bank for International Settlements (BIS) Monetary and Economic Department, [online] <URL: https://www.bis.org/publ/plcy04.pdf>

Federal Reserve Banks (n.d.): FEDGlobal, ACH Payments, [online] <URL: https://www.frbservices.org/assets/financial-services/ach/fedglobal-achpayments.pdf $>$

Guttmann, B. (2014): The Bitcoin Bible, Gold Edition: All you need to know about bitcoins and more. Amazon, Kindle Edition ASIN: B00I17S3CG 438. p.

Nakamoto, S. (n.d.): Bitcoin: A Peer-to-Peer Electronic Cash System. [online] <URL: https://bitcoin.org/bitcoin.pdf>

National Bank of Romania (2016) ReGIS. [online] <URL: http://www.bnr.ro/ReGIS-3305.aspx>

Schropfer D.W. (2010): The SmartPhone Wallet: Understanding the Disruption Ahead. Amazon, Kindle Edition, ASIN: B004KABBCC 142. p.

Scott, S.V., Zachariadis M. (2012): Origins and development of SWIFT, 1973-2009. In: Business History, 54. 3. 462-482. p. doi: 10.1080/00076791.2011.638502

Thralls, J. (1916): The Clearing House: Facts Covering the Origin, Developments, Functions, and Operations of the Clearing House, and Explaining the Systems, Plans, and Methods Promulgated by the Clearing House Section of the American Bankers Association, New York: Clearing house section American bankers association, 79. p.

Wikipedia (n.d.): Magnetic ink character recognition. [online] <URL: https://en.wikipedia.org/wiki/Magnetic_ink_character_recognition>

Corresponding author:

\section{Andrea KRISKÓ}

Széchenyi István University

H-9026 Győr, Egyetem tér 1, e-mail: andrea.krisko@yahoo.com 